Mini Review

\title{
Recent Advances of Flexible Electrospun Nanofibers-based Electrodes for Electrochemical Supercapacitors: A Minireview
}

\author{
Haoqi Yang, Shuqing Kou* \\ Roll Forging Research Institute, School of Materials Science and Engineering, Jilin University, \\ Changchun 130025, PR China. \\ *E-mail: kousq@jlu.edu.cn.
}

doi: $10.20964 / 2019.08 .28$

Received: 18 March 2019 / Accepted: 28 May 2019 / Published: 30 June 2019

\begin{abstract}
Flexibility has been identified as the most important factor in the foldable or bendable electrochemical supercapacitors (ESs), which include: electrical double-layer capacitors, and pseudo-capacitors. In this minireview, electrospun polymeric nanofibers (PNFs) and carbon nanofibers (CNFs) based composite electrodes for flexible electrochemical supercapacitors are reviewed in detail. During the past three decades, various electrospun composite electrodes have been developed, and their advantages and disadvantages in ESs are discussed through extensive analysis of literature. Additionally, this paper also discusses and predicts some futuristic research directions based on results published in literature. It is no doubt that electrospinning technology will continue to play an important role in flexible supercapacitor technology.
\end{abstract}

Keywords: Flexible Supercapacitor; Electrospun polymeric nanofibers; Electrospun carbon nanofibers; Energy storage

\section{FULL TEXT}

(C) 2019 The Authors. Published by ESG (www.electrochemsci.org). This article is an open access article distributed under the terms and conditions of the Creative Commons Attribution license (http://creativecommons.org/licenses/by/4.0/). 